\title{
An ILP and simulation model to optimize search and rescue helicopter operations
}

\author{
Mumtaz Karatas (iD) ${ }^{1 *}$, Nasuh Razi ${ }^{2}$ and Murat M. Gunal ${ }^{1}$ \\ ${ }^{1}$ Industrial Engineering Department, Turkish Naval Academy, 34940 Tuzla, Istanbul, Turkey; and ${ }^{2}$ Institute of \\ Naval Science and Engineering, Turkish Naval Academy, 34940 Tuzla, Istanbul, Turkey
}

\begin{abstract}
Maritime search and rescue (SAR) operations, conducted for rendering aid to the victims in need of help at sea, play a crucial role in dropping the number of causalities. Therefore, it is of high importance to organize SAR operations properly. In this paper, we compose a hybrid methodology which combines optimization and simulation to allocate SAR helicopters. First, we build an integer linear programming (ILP) model to provide an effective deployment plan and use it as an input to a simulation model which includes constraints that the ILP model cannot tackle. Next, using a rule-based algorithm, we generate alternative solutions and seek better plans that exist in the vicinity of the ILP model solution. We perform our methodology on the historical incident data in the Aegean Sea region. Results show that the hybrid methodology we adopted leads to a more effective utilization of resources than the optimization model alone.
\end{abstract}

Journal of the Operational Research Society (2017) 68(11), 1335-1351. doi:10.1057/s41274-016-0154-7;

published online 9 January 2017

Keywords: resource allocation; search and rescue; discrete event simulation (DES)

\section{Introduction}

Coastal countries construct maritime search and rescue (SAR) organizations, generally coast guards, to respond incidents occurring in their own SAR responsible region. SAR helicopters constitute the most important resource of these organizations in the sense that they are the most effective vehicles to respond incidents at sea and/or transport the critically sick or injured to medical centers. Some of their advantages are as follows: the capability of air search for lost victims, the ability of shuttling rescue personnel, equipment, or supplies to the victim quickly; the reduction in patients' transport time to a medical center; the specialized equipment capability to respond incidents such as a fire; the reliable and durable operation capability (compared to SAR boats) in hostile environments (Grissom et al, 2006; Varol and Gunal, 2015). Due to those aforementioned advantages, helicopter requests to respond distress calls for SAR operations occur frequently, which in most cases aims to reach victims at sea quickly and transport them to the nearest treatment centers.

Disclaimer The views and conclusions contained herein are those of the authors and should not be interpreted as necessarily representing the official policies or endorsements, either expressed or implied, of any affiliated organization or government.

*Correspondence: Mumtaz Karatas, Industrial Engineering Department, Turkish Naval Academy, 34940 Tuzla, Istanbul, Turkey.

E-mail: mkaratas@dho.edu.tr
Thus, the leading factor in determining the allocation plan of SAR helicopters is proximity to the potential incident regions. Besides, these organizations need to determine the number and type of resources, station allocations, equipment and staff capabilities. In that case, determining where to locate SAR helicopter resources is undoubtedly a facility location/resource allocation problem.

The problem of how to locate facilities is that of a strategic one and popularly seen in private and public firms. Deployment of a new construction is costly and needs to take a number of factors into consideration such as the distance to potential customers, any kind of changes and the necessity of relocation in the long term. It is of high importance to conduct an analytic study due to the remarkable cost of changing decisions on facility locations. Along with the allocation of warehouses in private firms, that of emergency response systems, such as fire-fighting, ambulance and SAR operations in public sector, is the main application area of resource allocation problem. In the literature, a considerable number of studies have been held to deal with this challenge. These studies mainly consider distances between servers and customers, coverage level and economic issues. In addition, reaction time to distress calls in emergency response systems is also a common performance metric in most studies.

However, optimization models developed to solve the resource allocation problems involving "server-to-customer" type operations, such as fire-fighting, emergency incident response, first aid (ambulance services) and SAR at sea, do not account for effects of unexpected equipment breakdown and 
weather condition issues to the performance of optimal solution. In most real life situations, the performance is affected due to unexpected delays or unavailability of scarce resources. In this paper, we present an optimization study to allocate SAR helicopters to stations in the area of interest. Beyond conventional formulations for mathematical modeling, we adopted a hybrid methodology to tackle the abovementioned challenges. Considering the tactical aspects of the emergency response operations, we developed a three stage methodology which includes: (1) an Integer Linear Programming (ILP) $p$-median location analysis model to determine a base SAR helicopter allocation plan with the objective of minimizing total response time to incidents (distress calls). This optimization model incorporates multiple facility types, i.e., different SAR helicopters, and also considers the business rules of the SAR organization. (2) A discrete event simulation (DES) model which tests the performance of the analytic solution under more realistic settings. The DES model considers realistic weather conditions and equipment breakdowns which are tricky to handle in the ILP model. (3) An alternative resource allocation plan generating and testing practice to evaluate better plans that exist in the vicinity of the ILP model solution. In specific, this practice includes a simple rule-based algorithm to generate other feasible nearby allocation plans which can be tailored by the decision maker in accordance with his/her preferences. We then use our DES model to assess the performance of generated alternative solutions.

Hybrid modeling approaches in OR are popular due to the fact that "Union is strength." We mean that the advantage of one sole modeling approach can further be amplified by working with another modeling approach in order to solve problems in OR. In our case, we merged the power of ILP modeling with that of simulation. The former is famous for obtaining exact solutions, e.g., $p$-MP, while the latter is known as a flexible modeling method to cope with complexity. Simulation also serves well as a communication medium between the modelers, who have a solid grasp of the methods, and the decision makers, who know the domain area thoroughly. The main reason why we have chosen the "hybrid approach" is that; the simulation model is used as a communication medium between us and the decision makers in TurCG. A secondary reason is that future requirements that may arise in this problem domain, such as creating a decision support system, can be handled in a better way using simulation modeling.

This paper is structured as follows: the literature review of optimization and DES models in resource allocation problems in emergency response systems is presented in Section 2, and our methodology is explained in Section 3. In Section 4, we experiment and demonstrate the impact of our approach with respect to the Aegean Sea. Finally, we conclude our work in Section 5.

We expect this study to guide planners of SAR operations for effective utilization of resources and help relieve distress of humans in need of help at sea, particularly due to migrant crises at the Aegean Sea.

\section{Related work}

Allocation of emergency systems is a subproblem of the facility location/resource allocation problem. In this section, we summarize studies that handle emergency response systems using optimization and simulation methodology, stochastic modeling, followed by studies on SAR resource allocations.

In the literature, there are many types of methodology to deal with the resource allocation problem. Church and ReVelle (1976), Owen and Daskin (1998), Schilling et al (1993), Brotcorne et al (2003) and Hale and Moberg (2003) are some of the studies that have utilized traditional models for allocation problems in the last few decades. These works point out covering, center and median models. Coverage problems are comprised of two basic subproblems; namely, set-covering problems (SCP) and maximal covering location problems (MCLP). While SCP seeks the minimum number of facilities required to meet the desired coverage level, MCLP is rendered to maximize coverage level with a given number of facilities (Li et al, 2011). In addition to coverage level, travel distance to facilities is a measure of effectiveness in a number of problems, especially for allocating public buildings such as schools, hospitals and train stations. In $P$-center problem, the objective is to minimize the maximum distance between each demand point and facility, also known as the minimax problem. Differently, in $P$-median problems ( $p$-MP) the decision maker aims to allocate $p$ facilities in such a way that total distance traveled between demand points and facilities is minimized. Dantrakul et al (2014) apply median and center model to allocate waste system facilities in Chiang Mai city and 5 provinces of Northern Thailand. As emergency systems facility location problem applications, Jia et al (2007) utilize both covering, center and median models for allocating medical supply storage to distribute antibiotics, vaccines and drugs rapidly under a possible chemical, biological, radiological and nuclear (CBRN) terrorist attack in LA. These traditional models are efficient methods in accordance with the objective of decision makers. However, emergency systems such as fire-fighting, ambulance and SAR respond to distress calls if there is an idle resource available. Otherwise, waiting or delay happens and this is an undesired situation for a person in need of help. The hypercube model, introduced by Larson (1974), is a widely used methodology which comprises Markov Chain and queuing theory to allocate server-to-customer systems. Despite not being an optimization model, it gives an acceptable structure of facilities. Studies of Takeda et al (2007), Galvão and Morabito (2008), Iannoni et al (2009) and Toro-Diaz et al (2013) are appropriate applications of hypercube model to find out more.

Along with the analytical models, computer simulation is a particular approach for problems with stochastic parameters. Mould (2001) studies the effectiveness of evacuation plans for off-shore oil drilling stations solely by using DES, which is due to the stochastic nature of the problem domain. The author 
estimates the probability of evacuation within $\mathrm{N}$ hours. Simpson and Hancock (2009) review the last 50 years of OR in terms of emergency response and discuss the impact of OR applications including simulation on managing emergency organizations. They conclude that OR has enormous potential for the better management of emergency responses. In another review, Aboueljinane et al (2013) figure out that computer simulation models are utilized to improve the efficiency of emergency medical services, a prevalent server-to-customer system. They classify studies in accordance with the main steps of a model such as inputs, formulation, model architecture and outputs. DES is a widely used simulation method to consider systems that have state changes at discrete time intervals (Goldsman and Goldsman, 2015). Simulation optimization with DES is a preferred methodology to deal with problems that are complex and costly to evaluate. As an example of simulation optimization application on emergency response systems, Zhen et al (2014) apply DES optimization for deployment and relocating ambulances in Shangai. Their simulation model seeks to evaluate the efficiency of allocation plans in stochastic scene. Another accepted utilization technique of DES is to evaluate the performance and dynamic behavior of existing systems, those of emergency response in particular. System success criterion is to respond distress calls as quickly as possible; however, a number of matters such as heavy traffic, unexpected failures and lack of idle resource cause delay and affect the survival rates in possible catastrophic cases. Aboueljinane et al (2012) utilize DES to analyze seven scenarios, which comprises dynamic changes in existing Val-de-Marne department's emergency medical service with the aim of improving response time and compare results with the original organization. In a different study, Aboueljinane et al (2014) apply DES to improve the process of the same system, which aims to respond calls in $20 \mathrm{~min}$, with five different strategies. Similarly, Nogueira et al (2016) devote their efforts to minimize response times of emergency medical service (EMS) with DES. Similar to previous studies, they formulate a multi-objective optimization model to allocate ambulances and then use allocation plan of the optimization model as initial allocation in simulation model. They perform DES model to EMS of Belo Horizonte, Brazil, with dynamic changes in the number of ambulances, bases and hospitals in six different scenarios. In their study, Onggo and Karatas (2015) and Onggo and Karatas (2016) use simulation to measure the performance of maritime search operations. Considering different maritime search problems, the authors develop a test-driven simulation modeling which utilizes analytic formulas to verify and validate their model.

In our review of the literature pertaining to the allocation of resources in a stochastic environment, we encountered a number of studies which were generally concerned with optimal locations in cases where demands, distances or costs were random. In an early study, Ermoliev and Leonardi (1982) explore the stochastic nature of facility location problems and introduce the concept of random demand and trip pattern of the customers. They propose numerical stochastic optimization techniques and demonstrate their performances over a few cases of simple problems. Louveaux (1986) considers a stochastic $p$-MP model for the simple plant location problem and develop a two-stage stochastic program. In the stochastic version, the author assumes locations and facility sizes as the first-stage decisions, while assuming the allocation of available resources as those of the second stage. Similarly, in a more recent study, Louveaux and Peeters (1992) consider a two-stage stochastic problem formulation for a facility location problem where the demand, selling prices and costs of production and transportation are uncertain. In their proposed heuristic approach, the authors evaluate location decisions in the first stage and the assignment of demand in the second one. Berman et al (1987) develop two heuristic approaches for locating $p$ mobile services on a network in the presence of a queuing-like congestion. Assuming stochastic service time, they aim to find locations which minimize the total expected response time. In their study, Schütz et al (2008) study a stochastic facility location problem in which demand and costs are uncertain and the objective is to minimize the expected total cost of locating facilities. Unlike previous studies, this work assumes that facility costs are nonlinear. The authors formulate the problem as a two-stage stochastic programming model and propose a solution method based on Lagrangean relaxation. Tadei et al (2009) consider a stochastic $p$-MP where the cost for siting a facility is a stochastic variable with an unknown probability distribution and the goal is to minimize the expected total cost. Modifying from the original stochastic $p$-MP formulation, the authors develop a deterministic integer nonlinear problem to determine the optimal value of location variables. Interested readers may also refer to Louveaux (1993) and Snyder (2005) for detailed reviews on facility location in case of uncertainty.

As we narrow the scope of our review regarding SAR problems, we confront with a number of studies that consider the search theory. Abi-Zeid and Frost (2005) design a geographical decision support tool that applies search theory to determine the optimal search plan for the Canadian Forces in case of missing aircrafts, while Wysokiński et al (2014) develop a similar system that is concerned with the missing person's behavior for the Polish SAR teams. Breivik and Allen (2008) present a stochastic trajectory model which concerns motions of drifting objects and use it for the Norwegian Sea and the North Sea. Although the above-mentioned tools and systems support SAR operations in terms of maximizing detection probability of missing objects, they are not appropriate for allocation of SAR resources. In another study, Van der Meer et al (2005) use Data Envelopment Analysis (DEA) and regression analysis to evaluate the performance of UK Coast Guard centers.

However, studies on the allocation of maritime SAR resources are limited in the literature. Losea (1976) deals with the problem of determining USCG allocation plan from political and social science sights; with that, he does not 
follow an analytic approach. Nguyen and Kevin (2000) formulate a goal programming model which considers MCLP and $p$-MP to evaluate the service level of Canadian SAR operations. In addition, they utilize the simulation method with queuing theory to examine the operational performance of SAR aircrafts in accordance with the average time that incidents spend in queue. Radovilsky and Koermer (2007) develop an ILP model to allocate SAR boats into USCG stations. In their model, they utilize boats as variables and try to locate SAR boats optimally while minimizing the capacity deviation at each station. Also, their model does not permit assigning a boat for multiple demand points. Wagner and Radovilsky (2012) improve Radovilsky and Koermer (2007)'s work and develop a decision support tool with multi-objective Mixed Integer Programming (MIP) model, namely the Boat Allocation Tool (BAT) which results in an improvement on USCG fleet performance. They try to minimize the following three objectives: the deviation of supply from demand, the number of boat types at a station and the total cost. Using the historical data between 2007 and 2012, similarly, Razi and Karatas (2016) develop the Incident-Based Boat Allocation Model (IB-BAM) based on a multi-objective MIP model, and use deterministic incident data to optimize SAR boat allocations in the western region of Turkey. Venäläinen (2014) tries to evaluate emergency responses in the Gulf of Finland and utilizes GIS methods with wind and wave impacts on navigation. Wex et al (2014) develop a decision support tool for allocating rescue units to respond emergency situations. They formulate a binary quadratic optimization model with the aim of minimizing total completion time of weighted incidents. In addition, they call the problem as "Rescue Unit Assignment and Scheduling Problem (RUASP)" and state that the problem could also be designed as Multiple Traveling Salesman Problem (mTSP) and the parallel-machine scheduling problem with unrelated machines. In their study, Ai et al (2015) develop an integrated nonlinear optimization model which deals with location, allocation and configuration of maritime emergency response bases and vessels. They also generate a hybrid heuristic and genetic algorithm to solve the problem. Pelot et al (2015) consider the problem of locating Canadian Coast Guard (CCG) SAR boats optimally. In their study, they try to locate different types of boats with individual capabilities in accordance to historical incident data in Atlantic Canada.

In Afshartous et al (2009), they demonstrate optimization and simulation methodology to allocate the US Coast Guard air stations with the objective of minimizing total travel cost (distance). Firstly, they formulate the optimization model as $p$ Uncapacitated Facility Location Problem ( $p$-UFLP), a combination of $p$-MP and UFLP, and then utilize the simulation method to analyze the robustness of solution coming from optimization model. In their simulation model, distress calls are generated from an inhomogeneous Poisson process. Goerlandt et al (2013) define a model practically focusing the sea rescue operations as a multi-server and multi-customer queuing system. They conduct a DES model to assess the performance of The Finnish Lifeboat Institution's rescue organization that is operated by volunteers. They seek to allocate 29 boats to 11 different rescue stations along the Gulf of Finland. More importantly, the study has a number of contributions from the related works above. The model generates 21 different types of incident, coming from historical data, and imports wave conditions, which affect boats' operation capabilities, into the model with the objective of representing real-world states.

Earlier studies perform under pre-defined scenarios to evaluate the performance of systems in terms of criterion such as coverage, operation capacity, travel distance and response time. However, models in most of these studies do not contain real factors which cause waiting and delays in systems. In our work, we aimed contributing to this end and filling the gap by importing external factors which cause delays such as weather conditions and unscheduled failures in SAR vehicles. Handling these factors is difficult in analytical models, and therefore we added them in a simulation model which works with a robust optimization model.

\section{Methodology}

Rapid response to a victim at sea with appropriate resources is the main purpose of a SAR operation. In order to improve the success rate of those operations, decision makers should consider the key factors below while planning SAR resource allocations (Razi and Karatas, 2016):

- Historical incident data in the area of interest,

- Types and requirements of incidents,

- Resource availability,

- Environmental conditions,

- Station capabilities,

- Business rules of the organization.

In this study, we adopted a hybrid methodology as described in Figure 1. Our methodology aims to generate an effective SAR helicopter allocation plan while considering all key factors mentioned above.

The methodology includes three modules: In module 1, using an ILP model, we determine a base plan for the allocation of SAR resources. This plan is optimal in the sense that it ensures the minimum total travel distance. In particular, we seek answers to the following questions: Which stations among the candidates should be activated? What type and number of helicopters should be allocated to those stations? In the model, we group our decision variables as hard and easy (in order to facilitate generating alternative plans in module 3), hard being the station activation decisions and easy as the helicopter assignment decisions. We call activation decisions as "hard" in the sense that the problem becomes significantly easier to solve whether those variables are fixed or 


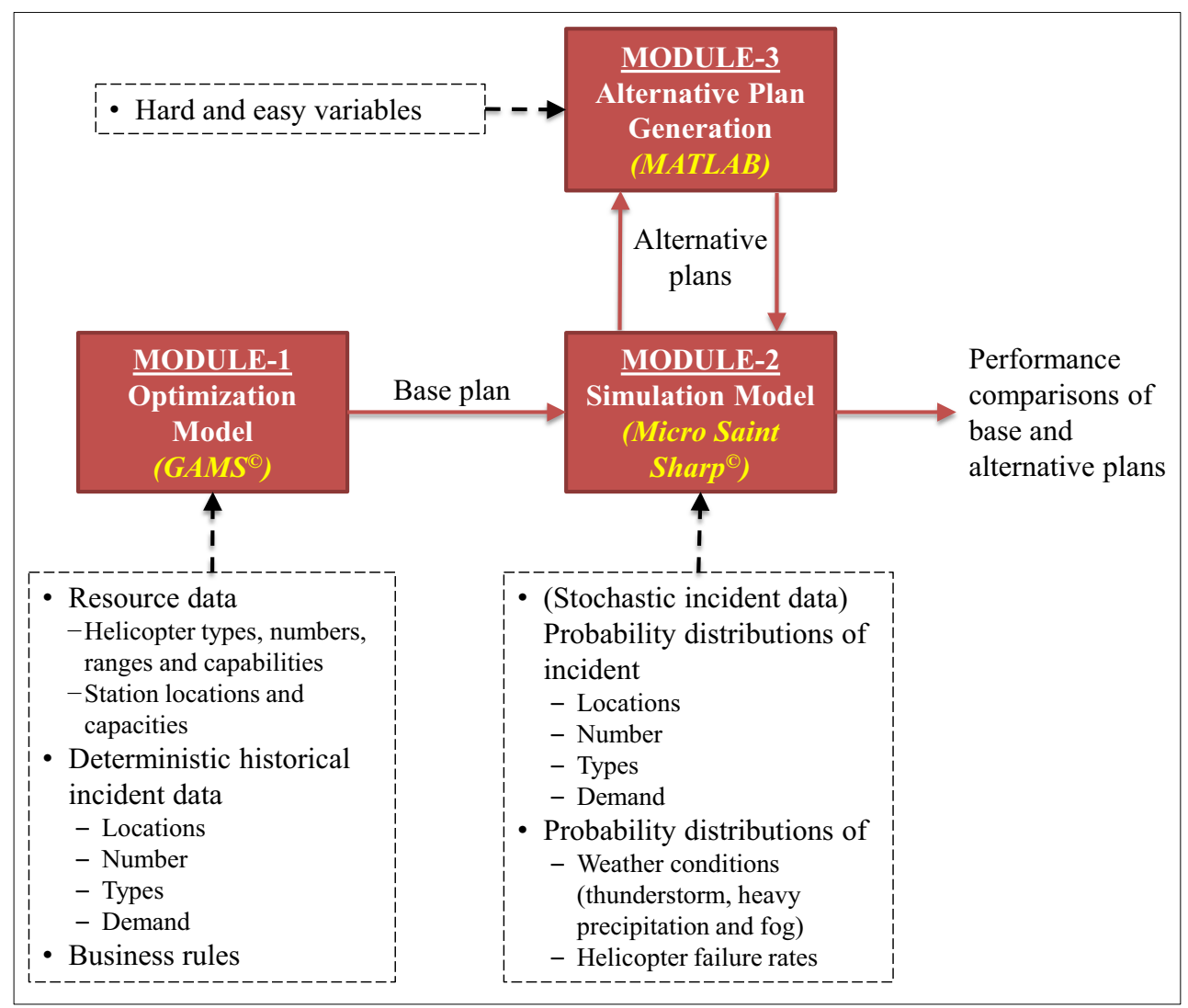

Figure 1 Flowchart of methodology.

predetermined. Also the decision of activating a station is far costlier than assigning helicopters to those stations.

Module 2 tests the performance of a given allocation plan via a DES model for stochastic incident data. It also considers environmental and equipmental factors, i.e., weather conditions, breakdowns, to create a more realistic scenario setting. We first test the effectiveness of the base allocation plan determined in the analytic model in module 1 with respect to a number of predetermined performance metrics.

In module 3, alternative plan generation (APG), we create alternative SAR resource allocation plans derived from the base allocation plan. The module creates plans by changing easy variables with respect to a number of criteria and rules, which will be explained later, while keeping hard variables fixed. In other words, utilizing the same stations as in the analytic result, we change types and numbers of helicopters at stations. While designing our alternative plans, we follow simple rules, based on the incident-dense areas, weather conditions and equipment breakdowns. Next, we measure the performance of alternative plans in module 2 and compare them with the base plan. In this step, our main ambition is to find out whether there are other solutions which are adjacent to the base plan and perform better under realistic scenario settings.

\subsection{Optimization model}

We formulate an ILP $p$-MP model for allocating helicopter resources to candidate stations. Our optimization model determines the stations to be activated as well as the number and type of helicopters to be deployed at each station. After discussions with the aviation and SAR experts in the Turkish CG, we decided to concentrate on the most common three types of incidents (operations): evacuation, search and fire. Although we implemented only two basic business rules, additional constraints can also be added to the model to implement other business rules. In the model, we also assumed that the demand is satisfied by a single resource and not spread over other resources, except for the case where fire incidents are responded by both fire and evacuation helicopters.

Regarding very large scaled problems, it is quite possible that ILP fails to provide a solution within a reasonable period of CPU time. However, we believe that ILP is an applicable and effective technique for solving maritime SAR resource allocation problems since the expected problem sizes are small enough for that technique. The studies Afshartous et al (2009) and Wagner and Radovilsky (2012) conducted for the USCG, the world's largest SAR operating fleet, also used ILP for optimal allocation planning. 
Our model is formulated with sets, indices, parameters, variables, objective function and constraints as explained below.

\subsubsection{Sets and indices}

$h \in H \quad$ Set of helicopter types

$s \in S \quad$ Set of candidate stations

$t \in T \quad$ Set of incident types \{evacuation, search, fire

$i \in I \quad$ Set of incidents (historical incidents data)

$I_{t} \subset I \quad$ Set of incidents of type $t$

$H_{t} \subset H$ Set of helicopter types that are appropriate for incident type $t$

\subsubsection{Parameters}

$d_{s i} \quad$ Distance between station $s$ and incident $i(\mathrm{~nm})$

$r_{h} \quad$ Max range of helicopter of type $h(\mathrm{~nm})$

$v_{h} \quad$ Operation speed of helicopter type $h(\mathrm{kts})$

$u_{i} \quad$ Demand of incident $i(\mathrm{~h})$

$A O_{h} \quad$ Annual operation capacity of helicopter type $h(\mathrm{~h})$

$C_{s} \quad$ Maximum helicopter capacity of station $s$ (unit)

$N_{h} \quad$ Total available number of helicopters of type $h$ (unit)

$K \quad$ Maximum number of stations that can be activated out of $|S|$ available stations. $(K \leq|S|)$

$\gamma_{\text {min }}$ Multiplier to provide the minimum total task time allowed on a yearly basis for a helicopter

\subsubsection{Decision variables}

$x_{h s}=$ Number of helicopters of typehallocated to stations.

(integer)

$y_{s}= \begin{cases}1, & \text { if station } s \text { is activated } \\ 0, & \text { otherwise }\end{cases}$ incident $i$ with the operation speed of helicopter type $h$. However, having sums in the objective function creates the risk of having long individual responses, while the aggregate is the shortest. Although long response times are undesirable in cases of emergency response, with the objective function of this type, the risk is unavoidable. On the other hand, we believe that we reduce that risk by the segmentation of incident and helicopter types. Furthermore, the results of the optimization model introduced here are not the finalized answers to the problem since they are reevaluated using different techniques in later stages of our proposed methodology.

\subsubsection{Constraints}

$$
\begin{gathered}
\sum_{s \in S} x_{h s} \leq N_{h}, \quad \forall h \in H \\
y_{s} \leq \sum_{h \in H} x_{h s} \leq C_{s} y_{s}, \quad \forall s \in S \\
x_{h s} \leq \sum_{i \in I} \lambda_{h s i}, \quad \forall h \in H, s \in S \\
\sum_{h \mid h \in H_{t}} \sum_{s \in S} \lambda_{h s i}=1, \quad \forall i \in I_{t}, t \in T \\
\sum_{h \mid h \in H_{\text {evacuation }}} \sum_{s \in S} \lambda_{h s i}=1, \quad \forall i \in I_{\text {fire }} \\
\lambda_{h s i} d_{s i} \leq r_{h}, \quad \forall h \in H, s \in S, i \in I \\
\sum_{i \in I} \lambda_{h s i} u_{i} \leq A O_{h} x_{h s}, \quad \forall h \in H, s \in S \\
\sum_{i \in I} \lambda_{h s i} u_{i} \geq \gamma_{\min } x_{h s}, \quad \forall h \in H, s \in S \\
\sum_{s \in S} y_{s} \leq K
\end{gathered}
$$

$$
\lambda_{h s i}= \begin{cases}1, & \text { if helicopter type } h \text { allocated in station } s \text { is assigned to incident } i \\ 0, & \text { otherwise }\end{cases}
$$

\subsubsection{Objective function}

$$
\min z=\sum_{h \in H} \sum_{s \in S} \sum_{i \in I} \frac{d_{s i}}{v_{h}} \lambda_{h s i}
$$

The objective function attempts to minimize total response time to incidents in the region. The response time is simply computed by dividing the distance between station $s$ and

$$
\begin{gathered}
x_{h s} \in\{0,1,2, \ldots\}, \quad \forall h \in H, s \in S \\
y_{s}, \lambda_{h s i} \in\{0,1\}, \quad \forall h \in H, s \in S, i \in I
\end{gathered}
$$

Constraint (2) ensures that, for a given helicopter type $h$, the number of allocated helicopters cannot exceed the total number available. Constraint (3) defines the $y_{s}$ variable and the respective station capacities. Constraint (4) prevents the 
allocation of unused helicopters. Constraint (5) makes sure that each incident is intercepted by an appropriate type helicopter. Constraint (6) is the business rule which dictates to assign an additional evacuation helicopter to fire incidents. This business is practiced by many SAR organizations for processing crew evacuation and firefighting at the same time. Constraint (7) provides that all incidents are responded by helicopters within their operation range. Constraint (8) ensures that demand supplied by a helicopter does not exceed its annual operation capacity. Constraint (9) determines the minimum allowable hours for each helicopter. Business rule for the maximum number of stations that can be activated out of $|S|$ candidates is represented in constraint (10). Constraints (11) and (12) declare variable types.

\subsection{DES model}

We identify maritime SAR processes as a customer-to-server queuing system in which incidents (demands) are customers and helicopters (resources) are servers. As we describe in Figure 1, the model includes stochastic parameters which the optimization model does not include. However, its main input is the output of the optimization model: the base helicopter allocation plan.

3.2.1. Inputs The simulation model consists of four sets of inputs: (1) probability distributions of incident demand, (2) weather conditions, (3) helicopter failures and (4) helipad station locations and helicopter numbers (resources).

To determine incident probability distributions, we use historical incident data of the area of interest. Although we assume that incidents are distributed random uniformly in an area, it is plausible to split the whole area into smaller and rectangular grids, in order to capture lands and risky regions. This ensures that each grid area has its individual incident pattern. We then analyze historical data that fall into each grid area to generate an incident inter-arrival time distribution. We assume that incident creation is a Poisson process; thus, the inter-incident time distribution for each incident type in a grid follows an exponential distribution with a mean of (1 year)/ (number of incidents of that type).

We utilize historical weather and helicopter failure data to determine probability distributions to be used as inputs to the simulation model. To the best of our knowledge, these features have not been included in a study before. Bad weather conditions, such as thunderstorm, heavy precipitation and fog, in vicinity of station, affect helicopters' operability and communication. Consequently, scheduled flights, and SAR operations, could be canceled or delayed due to weather conditions. Besides weather conditions, system failure in SAR vehicles is a factor which could affect SAR operations. Decision makers and surely helicopter crew could confront with a failure in a season despite the scheduled maintenance. During failure and maintenance times, SAR organization loses effort and possible incidents could not be intercepted. Thus, we import weather condition data and failure rates into the model for better representation of the reality.

As for the resources, we run the simulation model with the number of helipads and helicopters, and helicopter types, as in the optimization model. In addition, we define the list of operations that each type of helicopter/resource could intercept and the model prevents intercepting incidents with incapable helicopter/resources.

3.2.2. Process flow Maritime SAR operations start with a distress call received by an operation center. Decision makers in operation centers evaluate the situation and pass all information of the incident to the nearest helipad in which there is an idle helicopter. Helipad dispatches a capable helicopter with respect to the incident type. For example, decision makers must assign a helicopter which is equipped with fire-fighting capabilities to a fire incident. Helicopter conducts the operation until it is in need of refueling and then turns back to the helipad for refueling. After that, it goes on duty if required; otherwise, it stays in station for next duties.

In our work, we constructed the process flow shown in Figure 2. A SAR process begins with a generated incident. After an incident occurs, the model calculates distances from incident to each helipad and sorts them. Since the objective in our formulation is to minimize the total distance traveled, an incident entity checks the helipads in an ascending order for an idle resource. Through this process, if bad weather occurs or a failure happens, alternative idle resources are sought. We assume that weather conditions and failure affect only idle helicopters and do not block the existing process. If there is no idle capable helicopter, the incident enters the queue (FIFO) of the nearest helipad. The model works with the cycle mentioned above and collect all designated outputs.

3.2.3. Outputs We developed the model using Micro Saint Sharp@ version 3.7 simulation software, to generate the outputs listed in Table 1. Since the objective function in our study is to minimize the total travel time, some of the outputs listed below are derivatives of this amount, e.g., average total response time to incidents and to incidents satisfied. "Demand" is the amount of time needed on a scene to handle an incident. Other outputs include counts of incidents generated, responded and satisfied. Note that these outputs implicitly measure the effects of waiting times due to weather conditions and failures.

\subsection{Alternative plan generation (APG)}

Although our analytic model provides an effective solution to the problem, its performance may deteriorate in real-world settings. Hence, it may be possible to find alternative allocation plans that outperform the base plan under more realistic assumptions. The APG methodology is developed for providing 


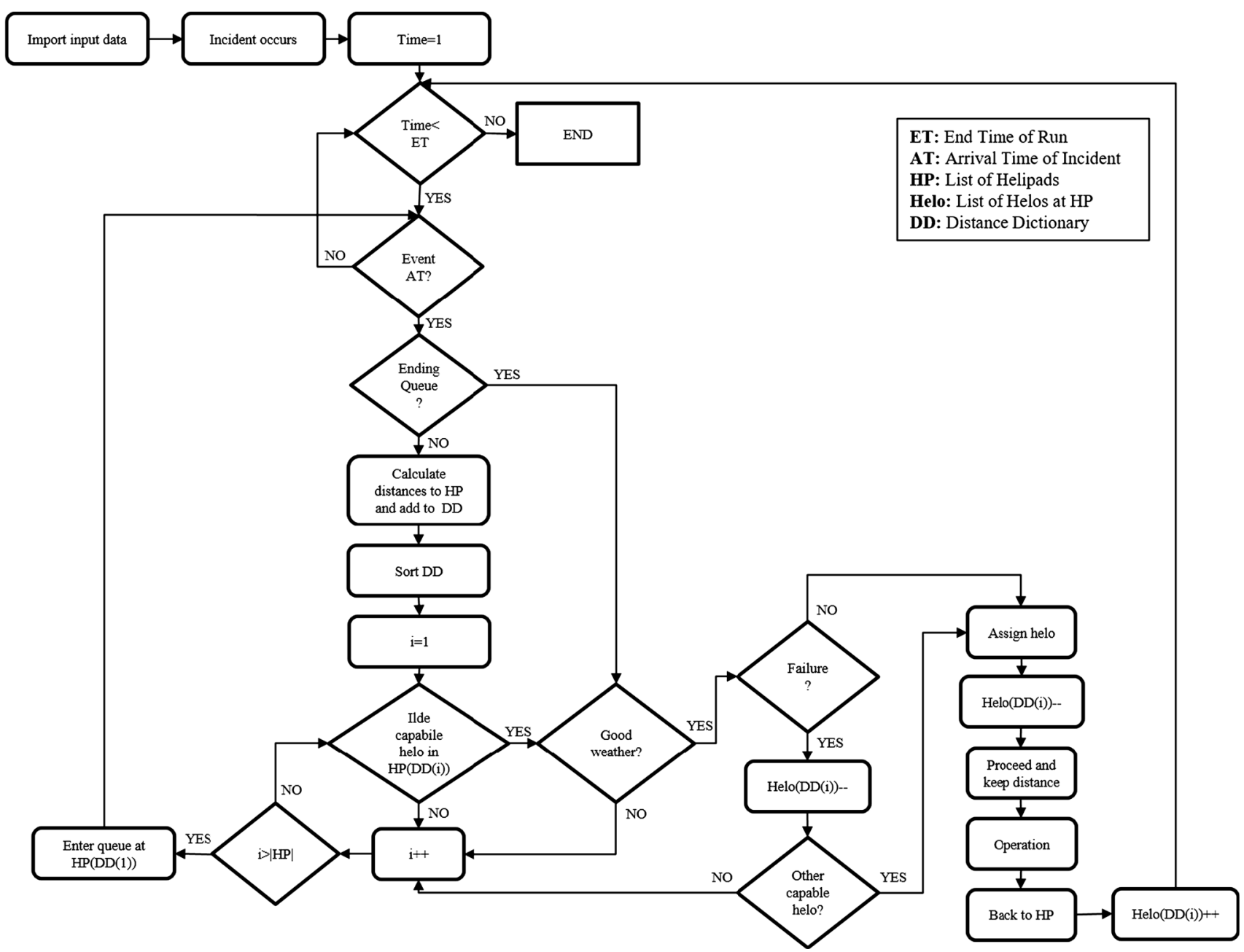

Figure 2 Flowchart of model.

Table 1 Simulation outputs

\begin{tabular}{|c|c|c|}
\hline $\begin{array}{l}\text { Output } \\
\text { ID }\end{array}$ & Model output & Definition \\
\hline$O_{1}$ & $\begin{array}{l}\text { Average total response time to } \\
\text { incidents }(\mathrm{h})\end{array}$ & Sum of response times to all incidents averaged over all simulation runs \\
\hline $\mathrm{O}_{2}$ & $\begin{array}{l}\text { Average response time to an } \\
\text { incident satisfied }(\mathrm{h})\end{array}$ & $\begin{array}{l}\text { Ratio of "total response time to incidents" to the "total number of incidents satisfied" } \\
\text { averaged over all simulation runs }\end{array}$ \\
\hline $\mathrm{O}_{3}$ & $\begin{array}{l}\text { Average ratio of incidents } \\
\text { responded }(\%)\end{array}$ & $\begin{array}{l}\text { Ratio of the "number of incidents responded" to the "number of incidents generated" } \\
\text { averaged over all simulation runs }\end{array}$ \\
\hline $\mathrm{O}_{4}$ & $\begin{array}{l}\text { Average ratio of demand satisfied } \\
(\%)\end{array}$ & $\begin{array}{l}\text { Ratio of "total demand satisfied" to the "total demand generated" averaged over all } \\
\text { simulation runs }\end{array}$ \\
\hline $\mathrm{O}_{5}$ & $\begin{array}{l}\text { Average ratio of incidents stand } \\
\text { in queue }(\%)\end{array}$ & $\begin{array}{l}\text { Ratio of incidents which cannot be responded due to helicopter unavailability, averaged } \\
\text { over all simulation runs. Such incidents enter the nearest stations' queue }\end{array}$ \\
\hline
\end{tabular}

decision makers with a number of candidate plausible allocation plans. This is achieved by making slight modifications to the base plan with some simple rules. It allows searching only a small fraction of the solution space that is focused on the region around the base plan. Although the APG approach presented in this study adopts simple steps and rules, it is possible to adapt more complicated and customized procedures.

APG adopts the allocation plan obtained from the optimization model. During the process, it is not allowed to change the values of the hard variables, i.e., activated stations; 
however, modification in soft variables, i.e., helicopter allocation plan, is allowed. Historical incident data are primarily used to determine incident-dense regions in the area of interest. Weather condition data, i.e., the number of days with thunderstorm, heavy precipitation and fog observed, are utilized to define the level of weather condition severity in the vicinity of a station.

The procedure starts with ranking the stations according to the severity of weather conditions observed at those locations. Next, it defines incident-dense regions and determines the nearest stations to those regions. The algorithm then starts shifting the faster and low-failure-rated helicopters located at severe stations to the ones with less severe conditions but higher incident density. The helicopter shifting step is repeated until all feasible plans are generated. The inputs, steps, rules and output of the procedure are listed below:

Inputs:

- Optimization model results (hard variables: activated stations, soft variables: helicopter allocation plan)

- Historical incident data (incident locations)

- Weather condition data (probability of canceling a flight with respect to weather conditions observed in a station.)

- Helicopter failure rates.

- Station capacities.

Plan generation steps:

- Step-1: Rank the activated stations (obtained from optimization model results) with respect to the probability of canceling a flight (obtained from weather data) due to weather conditions. High ranks denote critical stations with high cancelation probabilities.

- Step-2: Determine the most incident-dense regions and their closest activated stations.

- Step-3: Initialize the set of alternative plans $P$, as $P=\emptyset$ and set $i=1$.

- Step-4: Generate alternative plan $p_{i}$ :

Withdraw helicopter from a high-ranked station and deploy it to a lower-rank station by following the rules below:

- Rule-1: Among the lower-rank stations, give preference to the ones close to dense incident regions.

- Rule-2: Among the helicopters withdrawn, give preference to the ones with low failure rates and/or high operation speed.

- Rule-3: While shifting helicopters between stations, consider station capacities. (maintain feasibility)

- Rule-4: While shifting helicopters between stations, ensure that at least one helicopter remains at each activated station (maintain feasibility).
- Step-5: Set $P=P \cup\left\{p_{i}\right\}$ and $i=i+1$.

Outputs:

- Set of alternative helicopter allocation plans, $P$.

This algorithm is implemented for alternative plan generation module in Figure 1, and its task is to create the simulation experimental space.

The APG approach we use is similar to meta-heuristic algorithms in the sense that it disciplines the search direction in the solution space. It enables decision makers to measure the performance of neighbor solutions, improving the chance of finding a better plan than that of base. However, it is significantly different from those well-known heuristics in terms of its (1) goal and (2) stopping criteria. With regard to (1), APG does not aim to measure the performance of a solution, but rather creates a set of candidate solutions. Performance evaluation is left to the simulation model in step 3. As for (2), APG preprocesses the search space exhaustively within the vicinity of the base plan and stores it for further use. It finally stops when all neighbor solutions that satisfy the rules of decision makers are compiled.

\section{Case study}

The Aegean Sea has the heaviest marine traffic around the mainland of Turkey. As a result of its being the only way to reach the Black Sea, commercial and cruise ship traffic, as well as the leisure tourism, could be named as main reasons for traffic density. Figure 3 displays the historical data (obtained from Turkish Coast Guard (TurCG)) for the number of incidents occurred in the Aegean Sea between 2009 and 2014. The data reveals 1933 incidents, 716 of which were in 2014. This can be best explained by the turmoil in the Middle East started in 2013. That caused the Aegean Sea to become a preferred route for the immigrants to reach Europe illegally (UNHCR Global Appeal, 2015). There is no doubt that the increase in illegal border-crossing activities is the first and foremost factor which causes a remarkable rise in the total number of catastrophic cases. Besides, according to Miliou et al (2012)'s research, the boosting number of ships carrying hazardous material and the lack of designated shipping lanes are the other factors which increase the risk in the region.

According to Turkish National SAR Plan, TurCG is responsible for coordinating and conducting SAR operations in its responsibility region in the Aegean Sea coastline of Turkey. TurCG operates four different types of SAR helicopters in the region to respond distress signals from vessels in danger and there are a total of nine candidate stations for those helicopters. With the aim of enhancing the response time to incidents, we apply our methodology to determine effective locations for SAR helicopters in the western region of Turkey. 


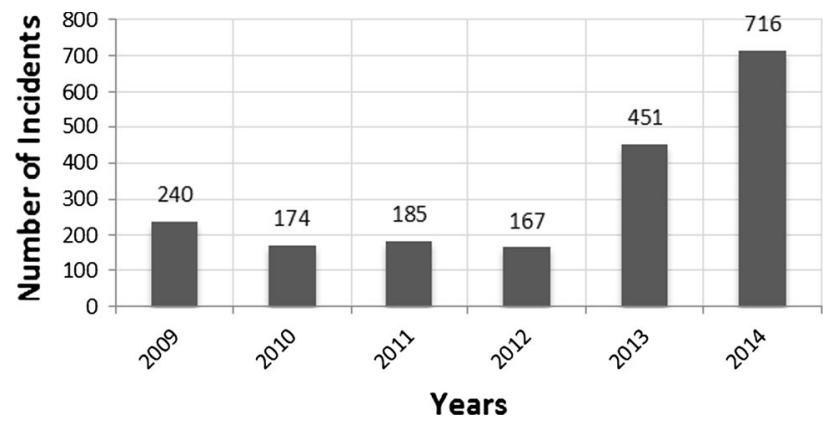

Figure 3 Historical incident data of the Aegean Sea.

\subsection{Input data}

TurCG uses four types of helicopters to conduct Aegean Sea operations. Key parameter values of these helicopters, including range, speed, capacity, are given in Table 2. Type-1, 2 and 3 can be used in evacuation and search operations, and for fire, only Type- 4 helicopters can be used. Weather conditions and equipmental breakdowns are other important factors that affect the performance of SAR operations in real world. Hence, our simulation model incorporates historical weather data, i.e., days with thunderstorm, heavy precipitation and fog, as well as failure rates for each helicopter type.

In specific, we count for the days when a helicopter is down due to an equipmental breakdown. The failure rate is basically used to determine the expected number of times a helicopter fails in a year, whereas the maintenance time represents how many days the helicopter will be inoperable. For confidentiality purposes, in this study, we do not present actual failure rate data of helicopters, but assume that failure rates and maintenance period distributions are the same for all helicopter types. Using Marlow and Novak (2013)'s results, we further assume that the failure rate fits a log-normal distribution with mean 3.1 and standard deviation 0.69 , and the length of maintenance period also fits a log-normal distribution with mean 1.77 days and standard deviation 0.92 days. For each four types of helicopter, the default annual operation capacity $A O_{h}$, measured in hours, is derived from the expected lifespan of helicopters. For confidentiality purposes, we name helicopters as Type-1, Type-2, Type- 3 and Type-4, and stations as $\mathrm{S} 1, \mathrm{~S} 2, \ldots, \mathrm{S} 9$.

There are nine candidate stations in the region that can be allocated with helicopters. However, five of those stations can be activated at most due to budget constraints. Hence, in our optimization model we set $|S|=9$ and $K=5$. Station capacities are summarized in Table 3.

In order to account for the worst case scenario, we solve the allocation problem by utilizing year 2014 data where the demand reaches its peak value among previous five years. However, for long-run planning purposes the model can easily be updated by substituting the demand data with its forecast. In cases where supply is severely constrained, one option for the TurCG policy would be to enhance the capabilities of the fleet in terms of flight crew number which would partially affect the annual operation capacity of helicopters. Another option might be to increase the number of stations that can be activated, which would result in a higher management cost but decrease the flight hour load on the fleet. Since these options are at a strategic level rather than tactical, we will not address such questions.

Locations, types and demands of all 716 incidents having occurred in 2014 and candidate stations are displayed in Figure 4 (left). After analyzing the incident data, we categorized them into three types of operations, of which 637 are evacuation, 43 are search and 36 are fire. To generate incidents stochastically, we partitioned the responsibility are into $0.25 \times 0.25$ degree-sized grids as shown in Figure 4 (right) It is clear that grids with more incidents represent high-risk regions.

Total number of incidents in a grid is utilized to determine inter-incident time distributions, and we assumed that incidents are random uniformly distributed in each grid cell.

Table 2 Key parameters of helicopter types

\begin{tabular}{|c|c|c|c|c|c|c|c|}
\hline $\begin{array}{l}\text { Helicopter } \\
\text { type }\end{array}$ & $\begin{array}{c}\text { Range } \\
(\mathrm{nm}) \\
\left(r_{h}\right)\end{array}$ & $\begin{array}{c}\text { Speed } \\
(k t s) \\
\left(v_{h}\right)\end{array}$ & $\begin{array}{c}\text { Minimum yearly } \\
\text { task time } \\
\left(\gamma_{\min }\right)\end{array}$ & $\begin{array}{c}\text { Annual operation } \\
\text { capacity }(h) \\
\left(A O_{h}\right)\end{array}$ & $\begin{array}{l}\text { Failure } \\
\text { rate } \\
\text { mean/sd } \\
\text { (times/ } \\
\quad \text { year) }\end{array}$ & $\begin{array}{l}\text { Maintenance time } \\
\text { (days) } \\
\text { mean/sd }\end{array}$ & $\begin{array}{l}\text { Incident types that can } \\
\text { respond }\end{array}$ \\
\hline Type-1 & 300 & 80 & 150 & 500 & $3.1 / 0.69$ & $1.77 / 0.92$ & Evacuation, search \\
\hline Type-2 & 400 & 120 & 150 & 400 & $3.1 / 0.69$ & $1.77 / 0.92$ & Evacuation, search \\
\hline Type-3 & 350 & 110 & 150 & 600 & $3.1 / 0.69$ & $1.77 / 0.92$ & Evacuation, search \\
\hline Type-4 & 750 & 90 & 100 & 800 & $3.1 / 0.69$ & $1.77 / 0.92$ & Fire \\
\hline
\end{tabular}

Table 3 Station capacities

\begin{tabular}{lccccccccc}
\hline Station & $S 1$ & $S 2$ & $S 3$ & $S 4$ & $S 5$ & $S 6$ & $S 7$ & $S 8$ & 59 \\
\hline Capacity $\left(C_{s}\right)$ & 7 & 7 & 5 & 9 & 5 & 5 & 4 & 8 & 10 \\
\hline
\end{tabular}




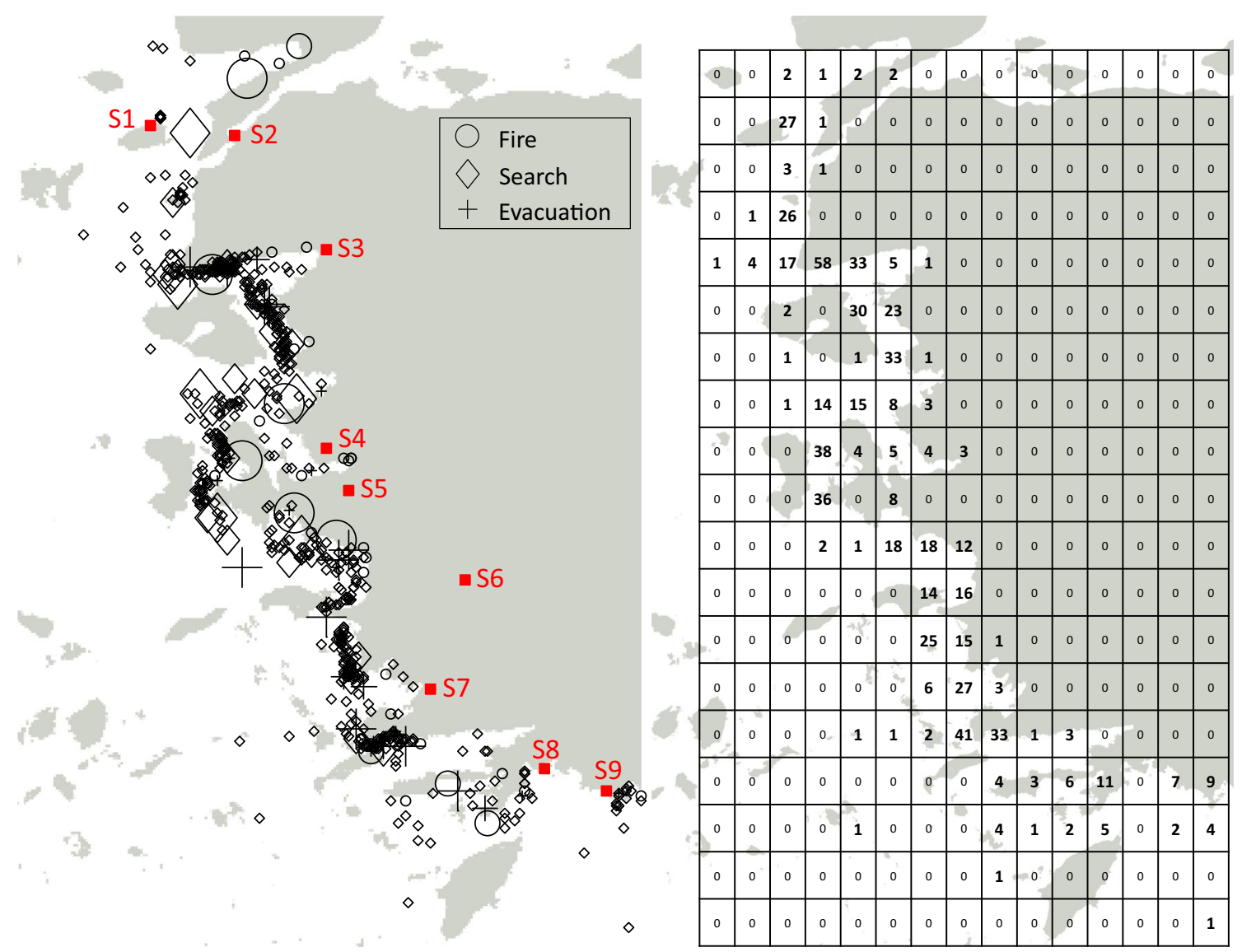

Figure 4 (Left) Incidents and candidate stations. The size of a marker is proportional to the amount of demand, i.e., small markers for demands $\leq 24 \mathrm{~h}$, medium markers for $24 \mathrm{~h}<$ demands $\leq 72 \mathrm{~h}$, and large markers for demands $>72 \mathrm{~h}$. (Right) Grid structure and number of incidents.

Furthermore, after the incident data analysis, we agreed to use geometric distributions for the time on scene (demand) with mean values of $64.55,8.46$ and $25.92 \mathrm{~h}$ for fire, evacuation and search incident types, respectively.

We used historical data provided by the Turkish State Meteorological Service (TSMS) for weather conditions to generate weather condition probability distributions. The data include weather conditions observed at each station in last 10 years. We assumed that a flight is canceled if bad weather conditions such as thunderstorm, heavy precipitation and fog occur at the station for which the flight was planned. Figure 5 shows the probability of observing (a) fog, (b) thunderstorm and (c) heavy precipitation in the vicinity of each station. The figure reveals that fog is mostly observed at the vicinity of station S2. Thunderstorms are particularly observed at the vicinity of station S9, while heavy precipitation is mostly observed at those of stations S2 and S7. After analyzing all weather data, the probability of canceling a flight due to bad weather conditions averaged over ten years is computed for every month in each station $s \in S$ as in Table 4 .

As expected, there is an evident relation among weather conditions, region and season. Figures 6 and 7 depict this relationship in detail. The data reveal that the probability of canceling a flight due to severe weather conditions is much higher in autumn and winter when compared to spring and summer (see Figure 6). The most severe weather conditions are particularly observed at the vicinity of S2 and S7 stations, along with the most southern station S9, yielding an average flight cancelation probability of $0.092,0.128$ and 0.069 , respectively. The probabilities remain steady between 0.024 and 0.039 for all other stations (see Figure 7).

\subsection{Analytic solution}

We solve our ILP model (for 716 incidents, nine candidate stations and four helicopter types) in the General Algebraic Modeling System (GAMSC) environment using CPLEX 12.2.0.2. The computational result shows that the branchand-cut search used by CPLEX finds the optimal solution (with the optimality gap of $0 \%$ ) within 79 CPU seconds on a computer with the following configurations: Intel Core i53330S CPU@2.70 Ghz with6.00 GB memory and Microsoft Windows 8.1 64-Bit operating system. Table 5 
(a)

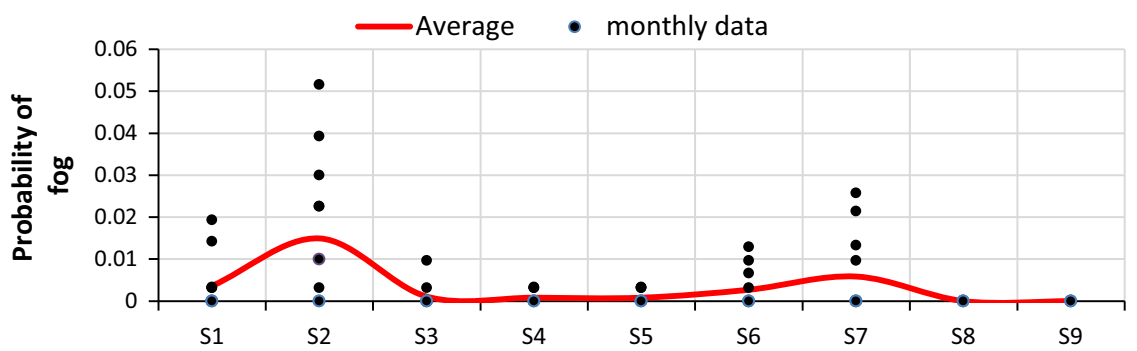

(b)

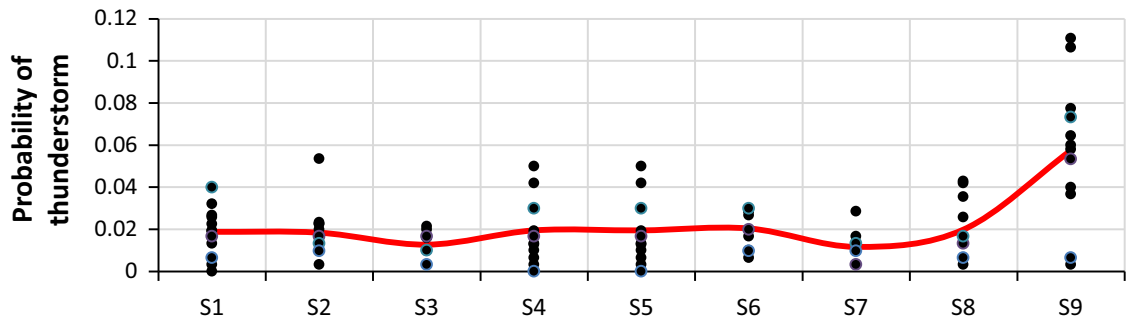

(c)

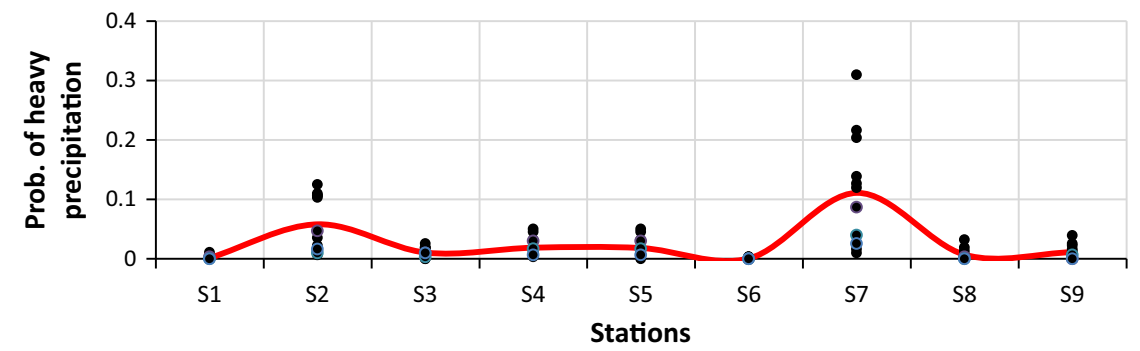

Figure 5 Probability of (a) fog, (b) thunderstorm, and (c) heavy precipitation in the vicinity of each station. Black disks and the solid line represent monthly and yearly averaged probability, respectively.

Table 4 Probability of canceling a flight on a day due to weather conditions

\begin{tabular}{|c|c|c|c|c|c|c|c|c|c|c|c|c|c|}
\hline Station & Jan & $\mathrm{Feb}$ & Mar & Apr & May & Jun & Jul & Aug & Sep & $O c t$ & Nov & Dec & Ave. \\
\hline 1 & 0.039 & 0.057 & 0.023 & 0.02 & 0.04 & 0.027 & 0.006 & 0 & 0.003 & 0.032 & 0.017 & 0.026 & 0.024 \\
\hline 2 & 0.184 & 0.218 & 0.148 & 0.073 & 0.023 & 0.03 & 0.026 & 0.026 & 0.03 & 0.055 & 0.147 & 0.139 & 0.092 \\
\hline 3 & 0.052 & 0.039 & 0.029 & 0.027 & 0.013 & 0.003 & 0.013 & 0.003 & 0.027 & 0.026 & 0.023 & 0.039 & 0.025 \\
\hline 4 & 0.077 & 0.1 & 0.065 & 0.047 & 0.047 & 0.017 & 0.006 & 0.006 & 0.037 & 0.013 & 0.027 & 0.029 & $\mathbf{0 . 0 3 9}$ \\
\hline 5 & 0.077 & 0.1 & 0.065 & 0.047 & 0.047 & 0.01 & 0.006 & 0.006 & 0.037 & 0.013 & 0.027 & 0.029 & 0.039 \\
\hline 6 & 0.042 & 0.029 & 0.013 & 0.02 & 0.03 & 0.013 & 0.01 & 0.01 & 0.027 & 0.029 & 0.023 & 0.042 & 0.024 \\
\hline 7 & 0.348 & 0.254 & 0.148 & 0.09 & 0.053 & 0.027 & 0.035 & 0.026 & 0.053 & 0.129 & 0.143 & 0.235 & 0.128 \\
\hline 8 & 0.061 & 0.075 & 0.032 & 0.017 & 0.017 & 0.017 & 0.006 & 0.003 & 0.013 & 0.039 & 0.03 & 0.013 & 0.027 \\
\hline 9 & 0.132 & 0.15 & 0.081 & 0.053 & 0.08 & 0.037 & 0.006 & 0.003 & 0.043 & 0.09 & 0.07 & 0.081 & 0.069 \\
\hline
\end{tabular}

summarizes the results (the activated stations and optimal (base) allocation plan of helicopters) with respect to the input data explained in Section 4.1. Results show that the optimization model recommends activating stations so that they are more or less evenly spaced along the coastline. Another important observation is that helicopters with higher speed (Type-2 and Type-3) are deployed at stations (S3, S4 and S7) near high-incident-density regions. This is an expected outcome since the objective is to minimize the total travel time. Note that we call this solution "base plan" in the simulation model.

Figure 8 summarizes both the breakdown of various incidents responded and the demand satisfied from activated stations with each helicopter type. The results show that helicopters are almost fully utilized in accordance with their annual operation capacities. $73 \%$ of total demand (h) and $89 \%$ of incidents are satisfied by high-speed Type- 2 and Type- 3 helicopters. Therefore, stations (S3, S4 and S7) in the midregion of the area of interest end up being the busiest stations with an overall demand satisfaction ratio of $78 \%$.

\section{3. $A P G$ and simulation results}

Using the input data and the optimization model results, we generated alternative plans by following the rules summarized 


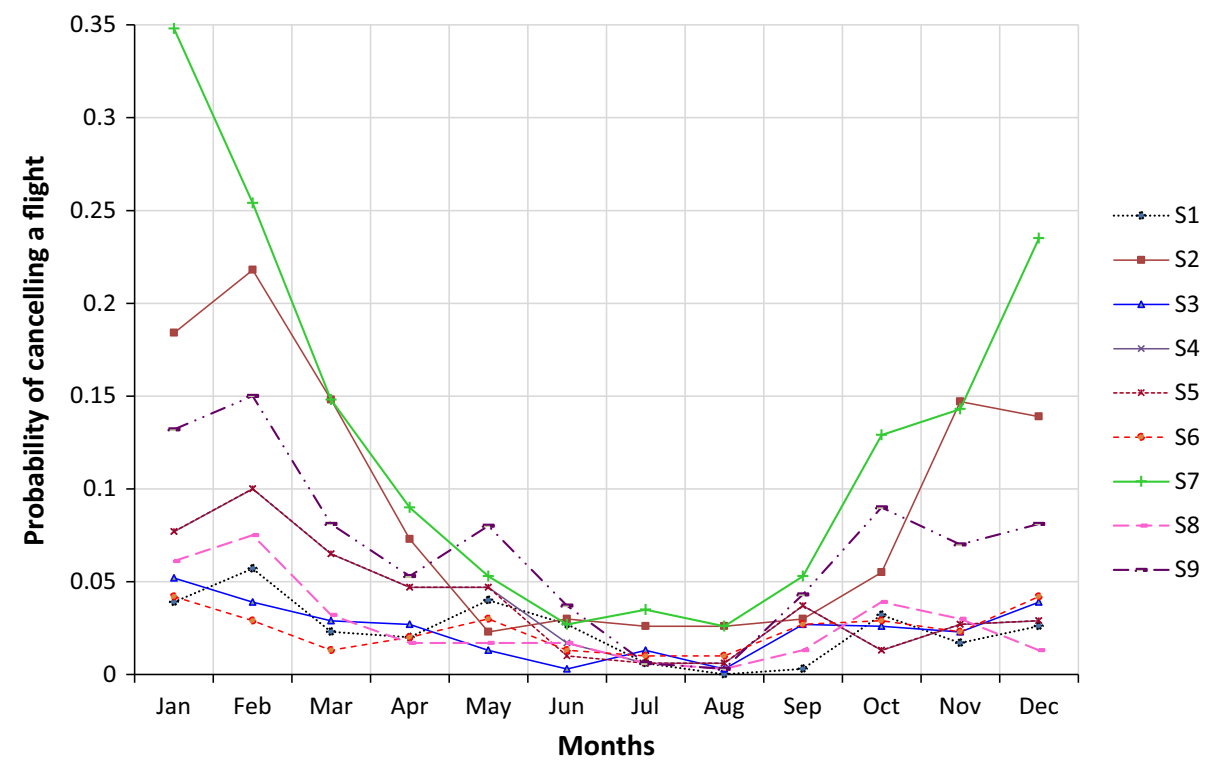

Figure 6 Probability of canceling a flight on a day in each month due to weather conditions.

in Section 3.3. In specific, among the activated stations, $\mathrm{S} 7$ has the most severe weather conditions in its vicinity. Stations S3 and S4 are located near incident-dense regions. Hence, the APG procedure recommends withdrawing helicopters (Type-3 is preferred) from $\mathrm{S} 7$ and deploying them to other stations ( $\mathrm{S} 3$, S4 and S8 are preferred).

Table 6 shows six alternative plans generated by APG procedure. For example, in plan 1, one Type-3 helicopter is shifted from S7 to S3. In plan 6, two Type-3 helicopters are shifted from $\mathrm{S} 4$; one of them to $\mathrm{S} 3$, and the other to $\mathrm{S} 8$.
We ran our simulation model for the base plan obtained from optimization model and collected results. After that, we tested all alternative plans suggested by APG procedure, which comprises dynamic changes in initial allocation, while stations are constant. All simulation runs are conducted in Micro Saint Sharp(C version 3.7. The simulation of each plan is performed 1500 times for one year. Table 7 shows performance metric values for the base plan under analytic and simulation models, as well as the simulation results for the six alternative plans mentioned in Table 6.

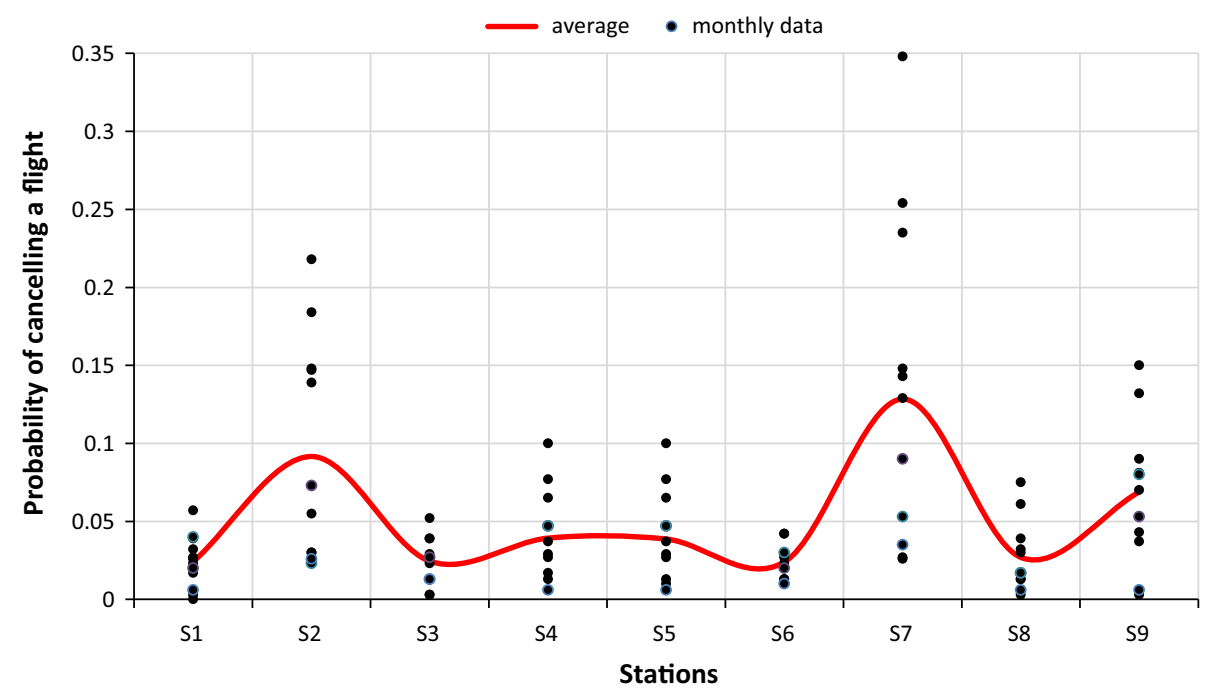

Figure 7 Probability of canceling a flight on a day for each station. Black disks and the solid line represent monthly and yearly averaged probability, respectively. 
Table 5 Results of optimization model

\begin{tabular}{|c|c|c|c|c|c|c|}
\hline \multirow[t]{2}{*}{ Activated station } & \multirow[t]{2}{*}{ Number of incidents responded } & \multirow[t]{2}{*}{ Demand $(h)$} & \multicolumn{4}{|c|}{ Number of helicopters assigned } \\
\hline & & & Type-1 & Type-2 & Type-3 & Type -4 \\
\hline $\mathrm{S} 1$ & 78 & 498 & 1 & - & - & - \\
\hline S3 & 181 & 1796 & - & - & 3 & - \\
\hline S4 & 227 & 3877 & - & 5 & 2 & 1 \\
\hline S7 & 204 & 2509 & - & - & 3 & 1 \\
\hline S8 & 62 & 1721 & - & 1 & 1 & 1 \\
\hline
\end{tabular}

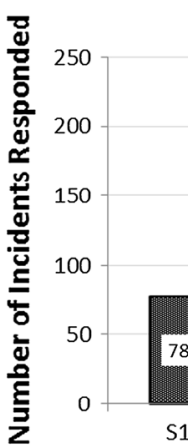

Type-1 $\mathbf{s}$ Type-2 $\mathbf{\square}$ Type-3 втуре-4

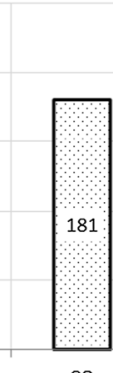

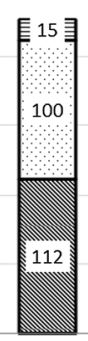

54

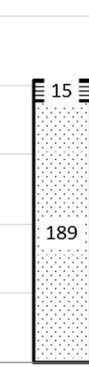

S7

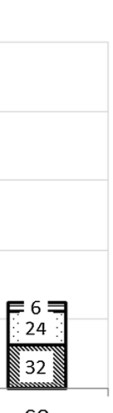

S8

Activated Stations

Figure 8 (Left) Breakdown of number of incidents responded from stations with each helicopter type. (Right) Breakdown of demand satisfied from stations with each helicopter type.

Table 6 APG suggested alternative plans (the superscript numbers represent the number of helicopters shifted to (+) and from (-) a station)

\begin{tabular}{|c|c|c|c|c|c|c|c|c|c|}
\hline \multicolumn{5}{|c|}{ Plan 1} & \multicolumn{5}{|c|}{ Plan 2} \\
\hline Station & Type-1 & Type-2 & Tyре-3 & Type-4 & Station & Tyре-1 & Type-2 & Type-3 & Type-4 \\
\hline S1 & 1 & - & - & - & $\mathrm{S} 1$ & 1 & - & - & - \\
\hline S3 & - & - & $4^{(+1)}$ & - & S3 & - & - & $5^{(+1)}$ & - \\
\hline S4 & - & 5 & 2 & 1 & $\mathrm{~S} 4$ & - & 5 & 2 & 1 \\
\hline S7 & - & - & $2^{(-1)}$ & 1 & S7 & - & - & $1^{(-1)}$ & 1 \\
\hline S8 & - & 1 & 1 & 1 & S8 & - & 1 & 1 & 1 \\
\hline \multicolumn{5}{|c|}{ Plan 3} & \multicolumn{5}{|c|}{ Plan 4} \\
\hline Station & Type-1 & Type-2 & Tyре-3 & Type-4 & Station & Type-1 & Type-2 & Type-3 & Type-4 \\
\hline S1 & 1 & - & - & - & $\mathrm{S} 1$ & 1 & - & - & - \\
\hline S3 & - & - & 3 & - & S3 & - & - & 3 & - \\
\hline S4 & - & 5 & $3^{(+1)}$ & 1 & S4 & - & 5 & 2 & 1 \\
\hline S7 & - & - & $2^{(-1)}$ & 1 & S7 & - & - & $2^{(-1)}$ & 1 \\
\hline S8 & - & 1 & 1 & 1 & S8 & - & 1 & $2^{(+1)}$ & 1 \\
\hline \multicolumn{5}{|c|}{ Plan 5} & \multicolumn{5}{|c|}{ Plan 6} \\
\hline Station & Type-1 & Type-2 & Tyре-3 & Type-4 & Station & Type-1 & Type-2 & Type-3 & Type-4 \\
\hline S1 & 1 & - & - & - & $\mathrm{S} 1$ & 1 & - & - & - \\
\hline S3 & - & - & $4^{(+1)}$ & - & S3 & - & - & $4^{(+1)}$ & - \\
\hline S4 & - & 5 & $3^{(+1)}$ & 1 & S4 & - & 5 & 2 & 1 \\
\hline S7 & - & - & $1^{(-2)}$ & 1 & S7 & - & - & $1^{(-2)}$ & 1 \\
\hline S8 & - & 1 & 1 & 1 & S8 & - & 1 & $2^{(+1)}$ & 1 \\
\hline
\end{tabular}


Table 7 Comparison of base plan and alternative plans

\begin{tabular}{|c|c|c|c|c|c|c|c|c|c|}
\hline \multirow[t]{2}{*}{$I D$} & \multirow[t]{2}{*}{ Output } & \multicolumn{2}{|c|}{ Base plan } & \multicolumn{6}{|c|}{ Alternative plans } \\
\hline & & Analytic & Simulation & Plan 1 & Plan 2 & Plan 3 & Plan 4 & Plan 5 & Plan 6 \\
\hline$O_{1}$ & Average total response time to incidents (h) & 204.243 & 218.032 & 239.417 & 206.433 & 221.083 & 190.216 & 209.133 & 222.833 \\
\hline $\mathrm{O}_{2}$ & $\begin{array}{l}\text { Average response time to incidents satisfied } \\
\text { (min) }\end{array}$ & 17.115 & 19.643 & 21.281 & 19.085 & 20.534 & 17.371 & 18.841 & 21.241 \\
\hline $\mathrm{O}_{3}$ & Average ratio of incidents responded (\%) & 100 & 93.41 & 94.67 & 94.02 & 90.60 & 92.15 & 93.41 & 91.14 \\
\hline $\mathrm{O}_{4}$ & Ratio of demands satisfied (\%) & 100 & 93.36 & 94.59 & 93.98 & 90.59 & 92.15 & 93.37 & 92.99 \\
\hline $\mathrm{O}_{5}$ & Average ratio of incidents stand in queue $(\%)$ & - & 4 & 4 & 3.2 & 3.5 & 4.4 & 3.3 & 4.1 \\
\hline
\end{tabular}

The results show that analytic solution performs slightly worse than expected when tested under realistic assumptions. The total response time $\left(O_{1}\right)$ increases by $6.8 \%$, whereas the average ratio of incidents responded $\left(\mathrm{O}_{3}\right)$ and the ratio of demands satisfied $\left(\mathrm{O}_{4}\right)$ decreases by $7 \%$. Also $4 \%$ of the incidents cannot find an available helicopter at the time of incident and stand in queue. The most important result is that among candidate plans, plans 2 and 5 dominate the base plan in terms of all five outputs. In particular, plans 2 and 5 end up with $5 \%$ and $4 \%$ less total response time $\left(O_{1}\right)$ than the base plan, respectively. The average response time to incidents satisfied $\left(\mathrm{O}_{2}\right)$ is also decreased by $3 \%$ and $4 \%$. Both plans perform almost equally with the base plan in terms of incident $\left(\mathrm{O}_{3}\right)$ and demand $\left(\mathrm{O}_{4}\right)$ satisfaction ratios. Finally, plans 2 and 5 perform $25 \%$ and $21 \%$ better, respectively, in terms of average ratio of incidents stand in queue $\left(\mathrm{O}_{5}\right)$.

\section{Discussion}

Operational Research and Management Science (OR/MS) community can benefit from utilizing hybrid methods, and this study may serve as an example. Mathematical modeling, one of the strongest tools in OR/MS toolbox, is able to come up with the exact solution of a "well-defined" problem. However, not every problem in real world can be well defined, and in such cases, other tools in the toolbox may help. For example, a time-related constraint that can be hard to include in a mathematical model may be an easy one for a simulation model. Likewise, methods in data analytics, an emerging area, can ease setting inputs to a mathematical model. Modelers, particularly, can benefit from using different or hybrid methods for solving problems in OR/MS.

As a consequence of this study, we can argue that a mathematical model can be supported by a simulation model to achieve realistic and convincing outcomes. In our case, the simulation model has added weather conditions and failure concepts to the problem, and this altered the base solution provided by the mathematical model. Furthermore, the simulation model helped reduce the risk of getting long response times suggested by the mathematical model.

The most distinctive outcome of this study is that it is possible to determine improved solutions (compared to the analytic solution) by implementing the combined optimization and simulation model with the proposed APG methodology. Our results showed that, among a small but high-quality fraction of the search space generated by APG, alternative plans 2 and 5 outperform the analytic solution in terms of all outputs under more realistic settings. The numerical results proved that the proposed methodology would enable strategic decision makers to measure and improve the performance of their SAR organizations.

\section{Conclusion}

Helicopters are the most effective vehicles in maritime SAR operations to respond to incidents. They are deployed at base stations, called helipads, mostly on land to ease the logistics of operations. Two questions exist for the effective design of SAR operations; first, where to locate helipads, and second, how many and which type of helicopters to allocate to helipads. Although finding the right location for helipads is difficult, due to the cost of contraction and weather characteristics, it is easier to allocate helicopters to helipads. However, there are some factors and complications to consider for answering both of these questions.

In this study, we proposed a hybrid methodology to help relieve SAR operations' design issues, such as finding the location of helipads and allocating helicopters to helipads. Our methodology includes an ILP model which finds the optimal locations of helipads among candidate locations. This model is a $p$-MP model and aims at finding the configuration of helicopters to minimize total response time to incidents. The model takes different incident types, and hence the helicopter types, into account and tries to allocate the right number of helicopters to the right incident types. Moreover, some business rules, such as assigning an additional evacuation helicopter to fire incidents, are included in the model. The second part of our methodology is a DES model. This model simulates SAR operations with the base helipad configuration by considering two stochastic factors affecting SAR operations, namely weather conditions and helicopter failures. Incident entities at random locations are created at random times, and helicopters assigned at helipads respond to incidents. Meanwhile, if there are bad weather conditions or 
helicopters experience failure, different helicopters are assigned. The third part of the methodology is to cover experimental space in DES model. We developed a rule-based algorithm based on operational experience to narrow the search space. For example, allocating more helicopters to helipads with low probability of canceling a flight due to weather conditions is a general rule of allocation.

We demonstrated our methodology in action using the Aegean Sea case. Among candidate station locations, we first determined the activated helipad locations on the west coast of Turkey and an allocation plan of helicopters. The model suggested to activate five helipads and allocated one Type-1, six Type-2, nine Type-3, and three Type- 4 helicopters to cover all incidents at minimum response time. Analysis of the historical incident data revealed high density regions as well as incident types in 2014 when the numbers peaked. Additionally, we worked on weather data to find out the probability of canceling a flight due to bad weather conditions, by helipad and month of year. We then simulated one year's operations with different allocation plans, and compared results with ILP model output. APG procedure helped us narrow the experiment area. Results showed that, under realistic constraints such as weather conditions and technical failures, ILP model results could be improved and more realistic results can be achieved.

We believe that this study contributes to the present knowledge at two levels. Firstly, at the methodological domain, it is unique in the sense that a hybrid of ILP, DES, and a novel APG method are used to solve a real-world problem. Secondly, at the application domain, SAR operation planning with helicopters, to the best of our knowledge, is studied in OR/MS context for the first time at the Aegean Sea where an effective SAR administration is needed urgently.

\section{References}

Abi-Zeid I and Frost J R (2005). SARPlan: a decision support system for Canadian Search and Rescue Operations. European Journal of Operational Research 162(3): 630-653.

Aboueljinane L, Jemai Z and Sahin E (2012). Reducing ambulance response time using simulation: The case of Val-de-Marne department emergency medical service. In: Proceedings of the Winter Simulation Conference, p. 84.

Aboueljinane L, Sahin E and Jemai Z (2013). A review on simulation models applied to emergency medical service operations. Computers \& Industrial Engineering 66(4): 734-750.

Aboueljinane L, Sahin E, Jemai Z and Marty J (2014). A simulation study to improve the performance of an emergency medical service: application to the French Val-de-Marne department. Simulation Modelling Practice and Theory 47: 46-59.

Afshartous D, Guan Y and Mehrotra A (2009). US Coast Guard air station location with respect to distress calls: a spatial statistics and optimization based methodology. European Journal of Operational Research 196(3): 1086-1096.

Ai YF, Lu J and Zhang LL (2015). The optimization model for the location of maritime emergency supplies reserve bases and the configuration of salvage vessels. Transportation Research Part E: Logistics and Transportation Review 83: 170-188.
Berman O, Larson R C and Parkan C (1987). The stochastic queue p-median problem. Transportation Science 21(3): 207-216.

Breivik $\varnothing$ and Allen A A (2008). An operational search and rescue model for the Norwegian Sea and the North Sea. Journal of Marine Systems 69(1): 99-113.

Brotcorne L, Laporte G and Semet F (2003). Ambulance location and relocation models. European Journal of Operational Research 147(3): 451-463.

Church R L and ReVelle C S (1976). Theoretical and Computational Links between the $p$-Median, Location Set-covering, and the Maximal Covering Location Problem. Geographical Analysis 8(4): 406-415.

Dantrakul S, Likasiri C and Pongvuthithum R (2014). Applied $p$ median and $p$-center algorithms for facility location problems. Expert Systems with Applications 41(8): 3596-3604.

Ermoliev Y M and Leonardi G (1982). Some proposals for stochastic facility location models. Mathematical Modelling 3(5) 407-420.

Galvão R D and Morabito R (2008). Emergency service systems: the use of the hypercube queueing model in the solution of probabilistic location problems. International Transactions in Operational Research 15(5): 525-549.

Goerlandt F, Torabihaghighi F and Kujala P (2013). A model for evaluating performance and reliability of the voluntary maritime rescue system in the Gulf of Finland. In: 11th International Probabilistic Safety Assessment and Management Annual European Safety and Reliability Conference. Amsterdam, pp. 1-6.

Goldsman D and Goldsman P (2015). Modeling and Simulation in the Systems Engineering Life Cycle. Springer, London, pp 103-109.

Grissom C K, Thomas F and James B (2006). Medical helicopters in wilderness search and rescue operations. Air Medical Journal 25(1): 18-25.

Hale T S and Moberg C R (2003). Location science research: a review. Annals of Operations Research 123(1-4): 21-35.

Iannoni A P, Morabito R and Saydam C (2009). An optimization approach for ambulance location and the districting of the response segments on highways. European Journal of Operational Research 195(2): 528-542.

Jia H, Ordóñez F and Dessouky M (2007). A modeling framework for facility location of medical services for large-scale emergencies. IIE Transactions 39(1): 41-55.

Larson R C (1974). A hypercube queuing model for facility location and redistricting in urban emergency services. Computers \& Operations Research 1(1): 67-95.

Li X, Zhao Z, Zhu X and Wyatt T (2011). Covering models and optimization techniques for emergency response facility location and planning: a review. Mathematical Methods of Operations Research 74(3): 281-310.

Losea RJ (1976). Planning, Programming and Budgeting for Resource Allocation in the United States Coast Guard. Department of the Navy, Naval Postgraduate School Thesis.

Louveaux F V (1986). Discrete stochastic location models. Annals of Operations research, $\mathbf{6}(2)$ : 21-34.

Louveaux FV (1993). Stochastic location analysis. Location Science 1(2): 127-154.

Louveaux FV, Peeters D (1992). A dual-based procedure for stochastic facility location. Operations Research 40(3): 564-573.

Marlow D and Novak A (2013). Fleet Sizing Analysis Methodologies for the Royal Australian Navy's Combat Helicopter Replacement Project (No. DSTO-TR-2886) Defense Science and Technology Organization Fishermans Bend (Australia) Joint and Operations Analysis Div.

Mould GI (2001). Assessing systems for offshore emergency evacuation. Journal of the Operational Research Society 52(4): 401-408.

Miliou A, Acasuso-Rivero C, Shepperson J, Lindholm A, Caprio C and Demetriou M (2012). Evidence of high risk maritime traffic 
conditions in the Aegean Sea. In 3rd International Conference on Industrial and Hazardous Waste Management, Crete.

Nguyen BU and Kevin YK (2000). Modeling Canadian search and rescue operations. Military Operations Research 5(1): 5-16.

Nogueira Jr LC, Pinto LR and Silva PMS (2016). Reducing Emergency Medical Service response time via the reallocation of ambulance bases. Health Care Management Science 19:31. doi:10. 1007/s10729-014-9280-4.

Onggo BS and Karatas M (2015). Agent-based model of maritime search operations: a validation using test-driven simulation modelling. In: Proceedings of the 2015 Winter Simulation Conference. IEEE Press, pp. 254-265.

Onggo B S and Karatas M (2016). Test-driven simulation modelling: a case study using agent-based maritime search-operation simulation. European Journal of Operational Research 254(2): 517-531.

Owen S H and Daskin M S (1998). Strategic facility location: a review. European Journal of Operational Research 111(3): 423-447.

Pelot R, Akbari A and Li L (2015). Vessel location modeling for maritime search and rescue. In: HA Eiselt, V Marianov (eds) Applications of Location Analysis (1st ed, pp. 369-402). Springer, New York.

Radovilsky Z and Koermer T (2007). Allocation of US Coast Guard boats utilizing integer programming. Journal of the Academy of Business and Economics 7(2): 130-135.

Razi N, and Karatas M (2016). A multi-objective model for locating search and rescue boats. European Journal of Operational Research 254(1): 279-293.

Schilling DA, Jayaraman V and Barkhi R (1993). A review of covering problems in facility location. Location Science 1(1): $25-55$.

Schütz P, Stougie L and Tomasgard A (2008). Stochastic facility location with general long-run costs and convex short-run costs. Computers \& Operations Research 35(9): 2988-3000.

Simpson NC and Hancock P G (2009). Fifty years of operational research and emergency response. Journal of the Operational Research Society 60: S126-S139.

Snyder LV (2005). Facility Location Under Uncertainty: A Review. Technical Report \#04T-015, Department of Industrial and Systems Engineering, Lehigh University, Bethlehem, PA.
Tadei R, Ricciardi N and Perboli G (2009). The stochastic p-median problem with unknown cost probability distribution. Operations Research Letters 37(2): 135-141.

Takeda RA, Widmer JA and Morabito R (2007). Analysis of ambulance decentralization in an urban emergency medical service using the hypercube queueing model. Computers \& Operations Research 34(3): 727-741.

Toro-Díaz H, Mayorga ME, Chanta S and McLay LA (2013). Joint location and dispatching decisions for Emergency Medical Services. Computers \& Industrial Engineering 64(4): 917-928.

UNHCR, Global Appeal 2015 Update. http://www.unhcr.org/ 5461e5f80.html.

Van der Meer RB, Quigley J and Storbeck JE (2005). Using data envelopment analysis to model the performance of UK coastguard centres. Journal of the Operational Research Society 56(8): 889-901.

Varol AE, Gunal MM (2015). Simulating prevention operations at sea against maritime piracy. Journal of the Operational Research Society 66(12): 2037-2049.

Venäläinen E (2014). Evaluating Voluntary Emergency Response in the Gulf of Finland. Doctoral dissertation. Helsinki, Finland: University of Helsinki, Department of Geosciences and Geography.

Wagner M R and Radovilsky Z (2012). Optimizing boat resources at the US Coast Guard: deterministic and stochastic models. Operations Research 60(5): 1035-1049.

Wex F, Schryen G, Feuerriegel S and Neumann D (2014). Emergency response in natural disaster management: allocation and scheduling of rescue units. European Journal of Operational Research 235(3): $697-708$

Wysokiński M, Marcjan R and Dajda J (2014). Decision support software for search \& rescue operations. Procedia Computer Science 35: 776-785.

Zhen L, Wang K, Hu H and Chang D (2014). A simulation optimization framework for ambulance deployment and relocation problems. Computers \& Industrial Engineering 72: 12-23.

Received 3 May 2016; accepted 15 November 2016 